\section{Emergency kit}

SIR,-The general practitioner is entrusted with primary medical care, which if properly carried out is a formidable undertaking. For this reason he needs support from several quarters-patients, hospital, administration. Take emergency calls.

Some 250000 attacks of myocardial infarction alone can be expected each year. Doctors have learned that the first two hours are crucial in such an attack, yet more often than not the vital hours are disregarded by patients themselves. What can the doctor do if he is not summoned in time, and why do prospective patients lack the necessary knowledge ? Heart attacks are not the only emergencies. Doctors can be confronted with an acute respiratory failure, status asthmaticus, tension pnuemothorax, anaphylactic shock, diabetic coma, dangerous convulsions, or other life-threatening conditions. Their efficiency and speed of action are essential in such circumstances; the suffering from acute retention of urine or renal colic can be immense. The rescuer has to be prepared and doctors involved in primary care have their emergency kits at the ready. But it is a rather haphazard affair. Different medical men have different ideas, some treatments are controversial, the general practitioner becomes confused. A doctor called out in the middle of the night may pick up a drug given to him the previous day by a pharmaceutical representative with a reassuring account. Which injections should be specially selected ? Practolol ? Atropine? Heroin ? Corticosteroids? Which are the most essential appliances-an airway or a suction pump, a catheter or a stomach tube ? An emergency kit must be handy, confined to essentials.

Despite the controversy about the standardised equipment for emergencies, or because of it, a panel of medical and pharmaceutical luminaries should come to the GP's aid and contrive one. It could be revised every four years or so. It worked with the British National Formulary; there is no reason why it should not work here. Family practitioner committees could help in supplying standardised emergency kits to individual practices at a non-profit-making price; I doubt if any GP would object to this.

C ROBERTS

Harrow, Middx HA2 6LY

\section{Poisoning and enuresis}

SIR,-We read with interest your leading article (17 March, p 705) on enuresis and the report by $\mathrm{Dr} A \mathrm{~J}$ Cronin and others on poisoning with tricyclic antidepressants ( $p$ 722). In the leading article you state that treatment should be reserved for older children and I would agree with this concept. When such a policy is adopted it is likely that by puberty less than $1 \%$ of children will require treatment. ${ }^{1}$ Parents are unlikely to accept such delays with equanimity, and it should be remembered that enuresis may be an indication of possible urinary tract pathology. Where simple measures fail in obtaining a cure then a more detailed examination should be undertaken. One of the most useful measures is the buzzer alarm ${ }^{2}$ but this instrument can result in the "non-enuretic" members of the family being awakened while the unfortunate sufferer remains asleep.

I would disagree with Dr A J Cronin and his colleagues when they state that "tricyclic antidepressants are the only drugs which are of any benefit." We have used a regimen of diuretic therapy with success in the management of enuresis when all other methods short of surgical intervention have failed. ${ }^{3}$

\section{R ScotT}

Urological Department, Royal Infirmary,
Glasgow G4 OSF

L MORRISON

Stobhill Hospital,
Glasgow G21 3 UW

' Gairdner, D, 1965, British Medical fournal, 1965, 2,
91.
${ }^{2}$ Meadow, R, British Medical fournal, 1977, 2, 1073.
${ }^{3}$ Scott, R, and Morrison, L, Journal of the Royal
College of Surgeons of Edinburgh, to be published.

SIR,-The solution to the problem of how to prevent the tragic and unnecessary deaths of enuretic children under the age of 5, discussed in your leading article (17 March, p 705), is basically simple but depends on the determination of those in whose power it lies to carry it out.

The solution is to treat the under-5s with the waking device, which, as you rightly say, renders $80 \%$ so treated permanently dry and yet is completely safe. To delay this treatment until 7 or later, as is often advised, will not save the younger children from the risks of poisoning; and in any case this delay is quite unnecessary, for young children respond to this treatment as well as the older ones.

Twenty years ago I started a clinic based on the waking device. It was open to enuretics of all ages and the results of the first 100 so treated were published (22 November 1958, p 1268). Among the under-5s $63 \%$ became completely dry within five weeks and $74 \%$ within 10 weeks. There were also two who were just under 3, both of whom became dry after only two rousings. These would have raised the cure rate to $80 \%$ but were not included since, by convention, they did not officially qualify as enuretics.

Thus the waking device can and therefore should be used at the earliest opportunity. It only remains to decide who should administer it. Not the children's hospitals-for they would be swamped with work, and besides they are too far away from many needing treatment. Nor should it be the GPs since many have already shown a reluctance to use it. The answer surely is that there should be clinics established in every district equipped with adequate apparatus and supervised by health visitors or nurses, and it should be widely known throughout the district that these clinics are prepared to treat enuretics of any age from 3 years old upwards. This would virtually abolish these iatrogenic poisonings, which have increased so greatly of recent years, and at the same time bring relief to countless families to an extent not previously achieved.

Paradoxically, the tricyclic compounds, which in excess can prove so lethal, should be employed at these clinics-but their use would be restricted to those who failed to be aroused by the waking device, and the dose given would tend to be lower than that often given to suppress bed-wetting (for example, for a child of $510 \mathrm{mg}$ of imipramine rather than 25 $\mathrm{mg}$ ). In some subtle way these preparations often seem to normalise the sleep pattern so that those who were deep sleepers and failed to respond to the alarm now do so and become permanently dry like any other bed-wetter. Thus the cure rate should rise even higher but with minimum risk if the use of tricyclic compounds were confined to clinics fully aware of the potential dangers.

T H Gillison

Ilkeston, Derbyshire DE7 5HL

SIR,-Yet again your pages (17 March, p 722) bear witness to the tragedy of poisoning with tricyclic antidepressants in childhood. The quantity ingested is likely to be larger when the tablets are prescribed not for the child but for an adult relative. The drug prescribed for the adult should be dispensed in childproof containers if young children have access to it.

In one of our cases recently, a girl of nearly 4 years ate all 35 of the $50 \mathrm{mg}$ imipramine tablets prescribed for her mother's enuresis. Two hours later she arrived in hospital deeply comatose, hypotensive (systolic pressure $50 \mathrm{~mm} \mathrm{Hg}$ ), and hypothermic. Her electrocardiogram showed right bundle-branch block and two atrial premature beats in trigeminy with each sinus beat. Soon she progressed to grade I atrioventricular block (PR interval $0.36 \mathrm{~s}$ ), with a sinus rate of 60 beats $/ \mathrm{min}$ interrupted irregularly by atrial premature beats. To pre-empt complete heart block and to treat arrhythmias, an endocardial electrode was introduced into the right ventricle through a cannula inserted in the right subclavian vein. At no site could a threshold of less than $2 \mathrm{~V}$ be found and this was accepted. The pulse generator was switched to $3 \mathrm{~V}$ and to the demand mode. Although left bundle-branch block was recorded at one stage, complete heart block never occurred. The patient went into a supraventricular tachycardia at a rate of 170 beats $/ \mathrm{min}$, however, with an unrecordable blood pressure; but control was obtained by overdrive pacing and an elective subsequent pacing rate of 120 beats $/ \mathrm{min}$. She made an excellent recovery despite the large dose of drug taken and about five hours of poor cardiac output.

With appropriate measures, a favourable outcome has been reported ${ }^{1}$ even in a child with a critically low cardiac output requiring continuous cardiac massage for two-and-a-half hours. We avoided using antiarrhythmic drugs because we feared that their negative inotropic effect on a depressed myocardium might be catastrophic. Fortunately, overdrive pacing was repeatedly successful. We would emphasise, however, the need to accept a moderately high pacing threshold in a poisoned heart. Frequent checks (every two to four hours, for example) of the threshold allow the pacing voltage to be reduced as recovery occurs.

G MCENERY R S WINWOOD

Whipps Cross Hospital,
London E11 1NR

1 South, D P, and Kilpatrick, S M, British Medical fournal, 1974, 4, 508 .

\section{Tricyclic antidepressant poisoning}

SIR,-Dr A J Cronin and others (17 March, p 722) have rightly drawn attention to the dangers that can arise in childern from the accidental ingestion of tricyclic antidepressant drugs. However, I feel that their case report and conclusions deserve further comment.

They describe the difficulties of treating massive overdosage with these drugs and indeed their patient received at least three different agents intended to reverse cardiotoxicity. No account was given, however, of the respiratory state of the child. The importance of this has been shown in two recent studies. Sutherland $e t$ al ${ }^{1}$ compared 16 patients with tricyclic antidepressant poisoning with 26 
patients with barbiturate poisoning. They found that in both grades III and IV coma overdose with the two groups of drugs caused an equal degree of hypoxia, mainly through ventilation-perfusion imbalance. In a second study, of 113 deaths from tricyclic antidepressants occurring in hospital in 1976, only 42 patients were described as breathing normally and less than half of those with obvious respiratory depression and hypoxia were artificially ventilated. Although the majority of patients in this latter series were already severely affected on arrival in hospital, it seems likely that the mortality could have been reduced by more aggressive treatment of hypoxia (whether caused by respiratory depression, ventilation-perfusion imbalance, or repeated convulsions) and by the avoidance of negatively inotropic drugs, which would be expected to aggravate rather than improve tricyclic-antidepressant-induced cardiotoxicity.

The child described by Dr Cronin and his colleagues was given a saline emetic, the dangers of which have previously been discussed in your columns. ${ }^{3}$ I assume that this patient was not in fact hypernatraemic on admission to hospital.

Unlike the patient described in this case report, the majority of children admitted to hospital with tricyclic antidepressant poisoning have taken medication prescribed for other members of their family. In a study of 489 patients with tricyclic antidepressant poisoning, which included 92 children under 5 , it was found that only $12.5 \%$ of those in this age group had taken their own medication, compared with $50 \%$ in the age range 6-15. Packing antidepressants in child-proof containers may well reduce poisoning in toddlers. However, there are other equally dangerous medications prescribed for children and it is perhaps unjustified to single out the tricyclic compounds as requiring warning labels describing their "lethal properties." Indeed, such warnings might encourage some people to take them.

Poisons Unit, New Cross Hospital

London SE14 5ER

Sutherland, G R, Park, J, and Proudfoot, A T, Clinical Toxicology, 1977, 11, 403.

2 Crome, P, and Newman, B, fournal of the Royal Society of Medicine, in press.

British Medical fournal, 1977, 2, 977. Crome, P, and Newman, B, Postgraduate Medical
fournal, in press.

\section{"Therapeutic" salicylate poisoning in children}

SIR,-The dangers of imipramine poisoning in children and the role of doctors in prevention has been rightly stressed ( 17 March, pp 705 and 722). The fall in the number of deaths in children due to salicylate poisoning was noted. Death and severe illness due to salicylates still occur, however, and as this drug is available without prescription the following cases are of interest.

Case 1-This 5-month-old child developed symptoms of a viral upper respiratory infection seven days prior to admission and was given an unknown number of junior aspirin, but none in the 24 hours prior to admission. He developed tachypnoea the day before admission and a few hours before admission was seen at a nearby casualty department but not admitted. On admission to our unit he was febrile (temperature $39.9^{\circ} \mathrm{C}$ ) and his heart rate was $200 / \mathrm{min}$ and respiratory rate $60 / \mathrm{min}$. The chest was clear to auscultation. Initial investigations showed a marked metabolic acidaemia (pH 7.18, $\mathrm{PaCO}_{2} 3.59 \mathrm{kPa}(27 \mathrm{~mm} \mathrm{Hg})$, $\mathrm{PaO}_{2} 7.98 \mathrm{kPa}(60 \mathrm{~mm} \mathrm{Hg})$, bicarbonate $10 \mathrm{mmol}$ $(\mathrm{mEq}) / \mathrm{l}$, and base excess -17). The serum salicylate was $3.3 \mathrm{mmol} / \mathrm{l}(45.5 \mathrm{mg} / \mathrm{dl})$. He was treated with intravenous fluids and bicarbonate and made a full recovery.

Case 2-This 11-month-old boy received 16 junior aspirin tablets $(1200 \mathrm{mg})$ in the 24 hours prior to admission because of irritability attributed to teething. He became tachypnoeic 12 hours prior to admission. On admission he was severely dehydrated; his respiratory rate was $54 / \mathrm{min}$ and heart rate $160 / \mathrm{min}$. His chest was clear to auscultation. Blood gases were: $\mathrm{pH} 7 \cdot 11, \mathrm{PaCO}_{2} 2 \cdot 79 \mathrm{kPa}$ $(21 \mathrm{~mm} \mathrm{Hg}), \mathrm{PaO}_{2} 7.32 \mathrm{kPa}(55 \mathrm{~mm} \mathrm{Hg})$, bicarbonate $7 \mathrm{mmol}(\mathrm{mEq}) / \mathrm{l}$, and base excess -22 . Serum salicylate was $5.46 \mathrm{mmol} / \mathrm{l}(75.4 \mathrm{mg} / \mathrm{dl})$. He was treated with intravenous fluids and bicarbonate and he also made a full recovery. He had marked haematuria and a prolonged prothrombin time (patient 53.2 seconds, control 13.5 seconds).

Both children had near lethal poisoning. ${ }^{1}$ The dangers of accidental therapeutic poisoning with aspirin have been emphasised, ${ }^{2}$ but there were delays in recognising the correct diagnosis in case 1 . Both children received the drug for trivial reasons, and in both cases the mothers had bought and used the drug as a harmless symptomatic measure.

Salicylates are freely available in pharmacies and supermarkets. Childproof wrapping will not prevent such poisoning as is reported here. Packets of junior aspirin contain advice to parents to use aspirin in children less than 1 year old on medical advice. Doses are given for other children. There is no mention of the hazards. Aspirin has a limited place in paediatric practice and has no place in trivial illness. ${ }^{3}$ If this potentially dangerous drug is to remain freely available to the public, then clear warning of its dangers should be printed on the packets. It would be preferable to limit its availability.

A copy of this letter has been sent to the Commission for Review of Medicines.

Dr W R McAinsh kindly allowed me to publish details of case 1. Mrs Muriel Agnew gave helpful information and stimulated reporting of these cases.

Paediatric Department

I Mitchell

Monklands District General Hospital,

1 Done, A K, Pediatrics, 1960, 26, 800.
2 Craig, J O, Ferguson, I C, and Syme, J, British .

London, Lloyd-Luke (Medical Books) Ltd, 1975.

\section{Chronic subdural haematoma}

SIR,-In your leading article (17 February, p 433) entitled "Chronic subdural haematoma" you state that radioisotope imaging cannot be relied on as a diagnostic procedure-a view not taken by most neurosurgeons.

Information on the capabilities of radioisotope imaging compared with computerised axial tomography (CAT) in the diagnosis of chronic subdural haematoma is available in several reports. ${ }^{1-3}$ If these studies are pooled the following results are obtained: in 35 patients in whom the diagnosis was made at operation, CAT had a preoperative diagnostic accuracy of $94 \%$ and radioisotope imaging of $91 \%$.

Thus there is no doubt in these studies that the two modalities are comparable in accuracy. But if we take in to consideration the facts that with CAT the patient needs to be more co- operative, receives a larger dose of radiation, and is at greater risk from injected contrast material, then radioisotope imaging becomes a much more attractive diagnostic modality.

Philip Helliwell

Palmerston North Hospital, Palmerston North, New Zealand

' Alavi, A, et al, fournal of Nuclear Medicine, 1977, 18,64 . Alderson, P O, et al, Neurology (Minneapolis), 1976,

26, 803.
1976, 127, et al, American fournal of Roentgenology,
1971. $1976,127,171$.

$*_{*}^{*}$ Dr Helliwell is quite correct in pointing out the value of radioisotope imaging in the diagnosis of chronic subdural haematoma and perhaps we should have indicated that it has a value. Although he points to the comparability of results with CAT scanning, in some of the papers he refers to there is no comment about the age of the lesions and the reliability of the investigations, whereas an earlier paper $^{1}$ drew attention to the difficulty in diagnosis by isotope scanning in the haematomas of a younger age. Certainly if isotope scanning is available it is a reasonable investigation and may lower the chances of overlooking this remediable condition but, if the presence of midline shift demonstrated by CT scan is taken into account, isotope scanning cannot be relied on in the same way to exclude the diagnosis. Unfortunately the appearances on isotope scanning after infarction may mimic closely those of chronic subdural haematos, particularly when the calcified pineal is not visible on the skull radiographs. $-\mathrm{ED}, B M \mathcal{}$. Cowan, R J, et al, fournal of Neurosurgery, 1970,
32, 30.

\section{Red eyes and hypercalcaemia}

SIR,-I read with interest the report of the demonstration of two cases at the Royal College of Physicians of London (17 March, p 727). The second case, that of a 66-year-old white woman admitted with visual deterioration, aches and pains in the legs, and a left homonymous hemianopia, I found particularly fascinating. It was stated in the history that she had had excessive thirst and constipation for some time, and nine weeks before admission had developed red, watering eyes. She was subsequently found to be hypercalcaemic, and the red eyes and the hypercalcaemia were not explained by the postmortem diagnosis of Creutzfeld-Jakob disease.

Dr Michael Smith and myself reported a case in February 1976 of recurring red eyes due to a seasonal hypercalcaemia. ${ }^{1}$ Red eyes associated with hypercalcaemia are almost certainly due to metastatic crystallisation of calcium and phosphate and hydroxyapatite in the conjunctiva. ${ }^{2}$ I feel the "conjunctivitis" referred to by Professor W B Matthews in the discussion of the case was due to the hypercalcaemia and not in fact to Creutzfeld-Jakob disease or an infective process.

It was not stated how long the symptoms of thirst and constipation had been present, but it would appear that the lady had been hypercalcaemic for some time. Was the rise in serum calcium from $3.1 \mathrm{mmol} / 1(12.5 \mathrm{mg} / 100 \mathrm{ml})$ to $4.6 \mathrm{mmol} / 1(18.3 \mathrm{mg} / 100 \mathrm{ml})$ associated with increased exposure to ultraviolet light? Is it possible that the histological findings at necropsy were the effect of hypercalcaemia on neuronal tissue? It would certainly seem 